\title{
Systolic Blood Pressure and Physical Fitness in Security Personnel: A Cross Sectional Study
}

\author{
Nadya Gratia Juliawan', Listya Tresnanti Mirtha2* and Muchtarudin Mansyur ${ }^{3}$ \\ 'Faculty of Medicine Universitas Indonesia, Jakarta, Indonesia \\ ${ }^{2}$ Sports Medicine Division, Department of Community Medicine, Faculty of Medicine Universitas Indonesia, \\ Jakarta, Indonesia; tresnanti.listya@ui.ac.id \\ ${ }^{3}$ Ocupational Medicine Division, Department of Community Medicine, \\ Faculty of Medicine Universitas Indonesia, Jakarta, Indonesia
}

\begin{abstract}
Background: According to the duty, security personnel must take care of their health especially their cardiovascular function to do their job optimally. Measuring systolic blood pressure is one of several ways to determine the cardiovascular condition that will affecting security personnel performance. Purpose: To find the correlation between systolic blood pressure and physical performance (determined by the result of Cooper 12-minutes running test as one component of Kesamaptaan Jasmani test) among security personnel in Faculty Medicine of Universitas Indonesia. Methods: 35 security personnel who the blood pressure already measured were taking Cooper 12-minutes running test. The data analysis then processed using SPSS Version 20 and the analysis was done analytically. The normality of the data was analyzed using Saphiro-Wilk and the correlation between the variables was analyzed using Pearson (if normal) or Spearman (if abnormal). Result: The analysis showed the distribution of the systolic pressure data is abnormal $(p=0.000)$. The correlation between the two variables then analyzed using Spearman method. The result shows there is a really weak correlation between systolic blood pressure and cardiorespiratory performance (correlation $=-0.05$ ). According to another study, systolic blood pressure has significant correlations with power, muscular endurance, agility, and $\mathrm{VO}_{2}$ max. However, the weak correlation in this study may be due to other factors that also affecting the result i.e. age, and level of physical activity. Conclusion: Future investigations must be done with more samples and there may be other factors affecting the Cooper test result that can be explained.
\end{abstract}

Keywords: Cooper Test, Physical Performance, Security Officers, Systolic Blood Pressure

\section{Introduction}

Blood pressure is one of important components that determine someone's cardiovascular health, therefore a person's blood pressure should be kept within the normal range of less than $120 / 80 \mathrm{mmHg}^{1}$. Blood pressure consists of two components: systolic and diastolic. Every increase of $20 \mathrm{mmHg}$ systolic blood pressure doubled the risk of stroke and ischemic heart disease ${ }^{1}$.

High blood pressure or usually known as hypertension is one of the biggest health problem in Indonesia. Based on ministry of health data, $25.8 \%$ of Indonesian population have hypertension and unfortunately $0.67 \%$ of them are undiagnosed ${ }^{2}$. This data shows most people are unaware of suffering from hypertension therefore they are not getting treatment or keeping their diet so this condition slowly affecting their physical health.

The increasing risk cardiovascular abnormalities caused by high systolic blood pressure can be affecting people physical fitness and their physical fitness will affect the quality of their work. Security officer is someone who has a responsibility on maintaining the campus security, so this officer must have a good physical fitness. In Indonesia, to be a security officers they must follow the selection of physical fitness test called Kesamaptaan Jasmani. One component of this test is Cooper test (test run for 12 minutes) ${ }^{3}$.

Until today, in Indonesia there is no research that discusses the correlation between systolic blood pressure and physical test result that can be achieved by security officers. Therefore, author wants to know the relation between these two variables.

${ }^{*}$ Author for correspondence 
It is hoped that through this research, the public especially the security officers in Universitas Indonesia know the importance of keeping their systolic blood pressure in normal range.

\section{Methods}

This study is a cross-sectional study which is conducted to know the correlation between the systolic and Cooper test result achieved by security guards. The test was performed in Salemba UI field for one day. Subjects who meet the inclusion and excluion criteria will be included in the Cooper test. Blood pressure measurements will be done by health officers, and then they must doing the Cooper test in which they have to run non-stop for 12 minutes. Before conducting the Cooper test, the security guards warms up led by a gym instructor to avoid cramps.

Preparation included in this study: (1) Field officers including non-health officers in charge of Cooper test (measuring the time, recording the results), and medics in charge of measuring blood pressure and preparing for emergency assistance, (2) Equipment such as stethoscope and sphygmomanometer to measure blood pressure, whistle, chalks, stopwatch, tape as track marker, and paper to record the Cooper test result.

\subsection{Stages of this study}

Subjects completing the data themselves such as name, date of birth, phone number, age and gender. Subjects asked about their physical condition and their blood pressure measured to determine whether they are eligible to do the Cooper test. Noting the subject's systolic and diastolic blood pressure. Subjects warms up led by gym instructor. Subjects follow the Cooper test and the mileage obtained is recorded.

The data obtained will be analyzed using SPSS 20 for Windows Program. The independent variable of this research (systolic blood pressure) will be using a numeric scale with units $\mathrm{mmHg}$, while the dependent variable is the distance of Cooper tests also using numeric scale with units meter $(\mathrm{m})^{4}$. The data will be tested its distribution by Kolmogorov-Sminor on sample size more than 50, or Saphyro-Wilk on sample size less than 50. If the distribution of the data is normal, the correlation between the two variables will be tested by using Pearson method, whereas if the distributin of the data is abnormal, the correlation will be tested using Spearman method $^{4}$.

\section{Results}

The analysis showed the distribution of the systolic pressure data is abnormal $(p=0.000)$. The correlation between the two variables then analyzed using Spearman method. The result shows there is a really weak correlation between systolic blood pressure and cardiorespiratory performance $(\mathrm{r}=-0.05)$ (Table 1$)$.

From (Figure 1), we can conclude $60 \%$ of the subjects' systolic blood pressure are in normal range $(<120 \mathrm{mmHg})$, $29 \%$ are in stage 1 hypertension $(130-139 \mathrm{mmHg}$ ), and only $11 \%$ are in stage 2 hypertension (>140 $\mathrm{mmHg}$ ).

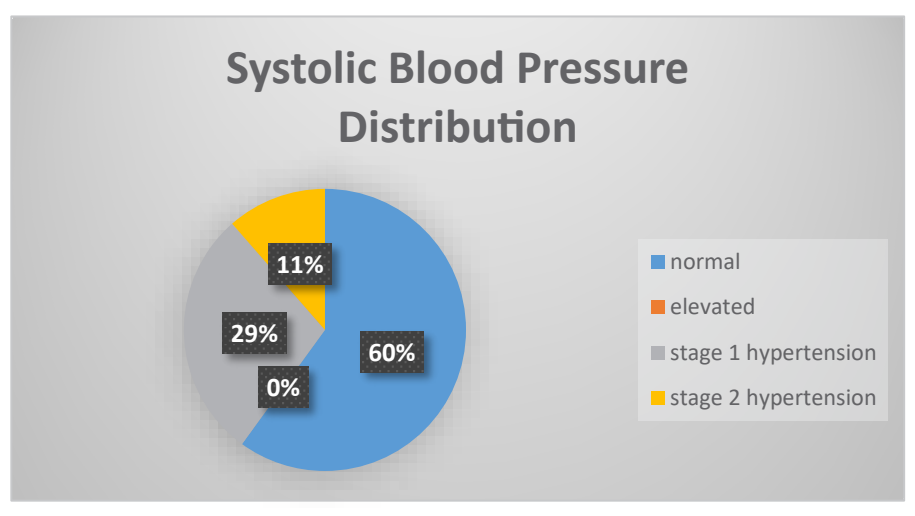

Figure 1. Distribution of subjects' systolic blood pressure.

\section{Discussion}

There are two components of blood pressure: systolic and diastolic blood pressure. Systolic blood pressure is the maximum pressure given to the arteries when blood is poured out of the heart, while diastolic blood pressure is the minimum pressure on the arteries when blood flows throughout the blood vessels when the heart is filling blood. ${ }^{4}$ An increase in systolic blood pressure can predict risk of cardiovascular diseases more sensitive than diastolic blood pressure. ${ }^{5}$ The farther the gap between systolic and diastolic blood pressure, the higher the risk of developing coronary heart disease. The

Table 1. Distribution of data included in this research

\begin{tabular}{|l|l|l|l|l|}
\hline Parameter & Mean (s.d) & Median (Min-Max) & $95 \%$ CI & p \\
\hline Cooper test distance $(\mathrm{m})$ & 1762,80 & - & $1676.34-1849.3$ & $-0.05^{\star}$ \\
\hline Systolic blood pressure $(\mathrm{mmHg})$ & - & $120(110-170)$ & $23.7677-26.1323$ \\
\hline
\end{tabular}

\section{Explanation :}

${ }^{\star}$ Spearmen correlation result shows no significant correlation between the variables

s.d = standard deviation; $\mathbf{C I}=$ confidence interval 
impact of systolic pressure on decreasing our heart health can be affecting a person's physical fitness given that the task of the heart is to supply blood throughout the body ${ }^{5}$. However, in this study it is found that there was no significant correlation between systolic pressure and Cooper's test distance that can be achieved by security personnel.

There are several reasons that might affecting the results of this study correlation. According to research conducted in United States, an increase in systolic blood pressure usually occurs when a person is 50 years or older because in older people the arteries are stiffening ${ }^{6}$. As the arteries stiffen, the systolic blood pressure will be increasing progressively. ${ }^{5}$ Meanwhile in younger people, the aortic wall is still flexible so it can minimize the pressure when the heart contracts. ${ }^{5}$ In this study the majority of the subjects are younger than 50 years old so there is no significant increase in their systolic blood pressure. This can be seen from the distribution of data where $60 \%$ of the subjects are in the normal blood pressure range $(<120 \mathrm{mmHg})$. In addition, the weak correlation in this study may also due to the small number of samples and the presence of confounding variables i.e. age and level of physical activity.

Based on previous study it is stated that as someone get older, the physical performance (grip strength, walking speed and FTSS (five times sit to stand test)) will be decreasing. The decrease in physical performance is due to the decrease in muscle mass and muscle strength as someone gets older?

Another factor that can also affecting the result is the level of physical activity of each subject. Research conducted by Hsieh and colleagues proved that there is positive correlation between physical activity and cardiorespiratory fitness. Although this study was conducted on groups of school children so it may could not be generalized into groups of adults, this study proved that physically active children had significantly higher physical fitness than inactive group ${ }^{8}$.

\section{Conclusion}

Future investigations must be done with more samples and another confounder variables for example age must be omitted by improving the inclusion criteria.

\section{Acknowledgement}

I would like to thank dr. Listya Tresnanti Mirtha, MD. SportsMed. from Sports Medicine Division, Department of Community Medicine, Faculty of Medicine Universitas Indonesia for allowing and encouraging me to run this study. In addition, we thank all doctors, staffs and security personnels of Faculty of Medicine University of Indonesia for their sincere help and encouragement.

\section{References}

1. Understanding blood pressure readings [Internet]. 2017 [cited 2018 Jun 18]. Available from: http://www.heart.org/HEARTORG/ Conditions/HighBloodPressure/KnowYourNumbers/ Understanding-Blood-Pressure-Readings_UCM_301764_ Article.jsp\#.WydJlSAyU1k

2. Kementerian Kesehatan Republik Indonesia [Internet]. 2017 [cited 2018 Jul 20]. Available from: http://www.depkes.go.id/ article/view/17051800002/sebagian-besar-penderita-hipertensitidak-menyadarinya.html

3. Tahapan Seleksi Kesamaptaan [Internet]. 2015. Available from: https://penerimaan.polri.go.id/rik_jasmani_a/1

4. Sherwood L. Human Physiology. 9th ed. Canada: Cencage Learning; 2016. p. 341.

5. Basile JN. Systolic blood pressure. British Medical Journal. 2002 Oct 26; 325(7370):917-8. https://doi.org/10.1136/ bmj.325.7370.917 PMid:12399325. PMCid:PMC1124431

6. Program NHBPE. Importance of systolic blood pressure [Internet]. National Heart, Lung, and Blood Institute (US); 2004 [cited 2018 Aug 8]. Available from: https://www.ncbi.nlm.nih. gov/books/NBK9632/

7. Makizako H, Shimada H, Doi T, Tsutsumimoto K, Lee S, Lee SC, et al. Age-dependent changes in physical performance and body composition in community-dwelling Japanese older adults. Journal of Cachexia Sarcopenia Muscle. 2017 Aug;8(4):607-14. https://doi. org/10.1002/jcsm.12197.PMid:28597612. PMCid:PMC5566639

8. Hsieh P, Chen M, Huang C, Chen W, Li C, Chang L. Physical Activity, Body Mass Index, and Cardiorespiratory fitness among school children in Taiwan: A cross-sectional study [Internet]. 2014 Jul 16. Available from: https://www.ncbi.nlm.nih.gov/pmc/ articles/PMC4113875/ 